\title{
Relationship Between Uptake of Antenatal Care Services and Low Birth Weight in the Gushegu District of Northern Ghana
}

\author{
Mahama Saaka* and Abdulai Abdul Rauf
}

\author{
University for Development Studies, School of Medicine and Health Sciences, P.O. Box 1883, Tamale-Ghana
}

\begin{abstract}
Abtract: Objective: Little is known about the relative contribution of prenatal care utilization on pregnancy outcome in developing country setting where other equally important predictors of low birth weight (LBW) including malarial infection and poor diet predominate. This study investigated whether the utilization of antenatal care (ANC) services is an independent predictor of LBW in Northern Ghana.

Methods: In this community based cross sectional study, we compared pregnancy outcome (birth weight) across groups of 407 women who received different amounts of ANC.

Results: The incidence of low birth weight (LBW) of newborn babies was $18.2 \%(74 / 407)$. The main finding was that women who made at least four ANC visits had $63.0 \%$ protection against delivering a LBW (AOR $=0.37,95 \% \mathrm{Cl}: 0.19$, $0.69)$.

Conclusion: The results of this study suggest that adequate antenatal care is effective in preventing LBW in a rural setting but its effect was more discernible among women who were not in gainful employment (suggestive of low socioeconomic status).
\end{abstract}

Keywords: Antenatal care utilization, Low birth weight, Birth weight, pregnancy, deprived environment, Northern Ghana.

\section{INTRODUCTION}

\section{Background}

Low birth weight (LBW) is a serious, international public health concern. It is estimated that over 20 million children worldwide are born with LBW and majority of these occur in developing countries [1]. LBW babies face greater mortality risk [2] and those who survive have higher probabilities of retarded motor development, neurological impairment and chronic illness [3, 4] and lower IQ, worse labor force and educational outcomes, and even pregnancy complications $[5,6]$.

To effectively address LBW, public health interventions that have the potential of improving birth outcomes need to be identified and implemented at large scale. One such intervention is prenatal care given to pregnant women. Prenatal care has been shown to successfully intervene and reduce instances of preterm birth and low birth weight mostly in industrialized countries [7-12]. The few studies that have been conducted in developing countries have produced inconsistent results as well. For example, a study conducted in Mexico found that early initiation of prenatal care had no impact on birth weight, while the

*Address correspondence to this author at the University for Development Studies, School of Medicine and Health Sciences, P.O. Box 1883,

Tamale-Ghana; Tel: 233-0207061136; E-mail: mmsaaka@gmail.com

E-ISSN: 1929-4247/13 number of visits had a large and positive effect [13]. Guilkey et al. [14] found both positive and negative effects on birth weight depending on geographical area, type of provider and facility where the care was supplied.

Prenatal care, commonly known as antenatal care (ANC) in most developing countries, is one of the key health interventions that have the potential to reduce morbidity and mortality among newborn babies and pregnant women. ANC provides an excellent opportunity to inform and educate pregnant women about pregnancy, childbirth and care of the newborn. Adequate ANC utilization is therefore expected to impact positively on pregnancy and birth outcome. Maximum benefit is however, derived if women initiate prenatal care in the first trimester of pregnancy and continue to receive care throughout pregnancy, according to recommended standards of periodicity [15].

Since 2003, the Government of Ghana has promoted access to maternal health services including prenatal care through the free maternal health policy and the establishment of Community Based Health Planning and Services (CHPS) compounds. These strategies are aimed at reducing the financial and physical barriers in using maternity services. Though there is improvement in prenatal care utilization, a significant proportion of women of reproductive age (15-49) years continue to initiate prenatal care late in pregnancy. Inadequate use of prenatal care services 
by women who could benefit the most from these services remains worrisome. The World Health Organization (WHO) recommends that a minimum of four antenatal visits should be made during pregnancies in order to take advantage of health services including blood pressure measurement, urine testing for detecting bacteria and protein in urine, blood testing to detect syphilis and severe anemia, weight and height measurements [16]. Villar et al. [17], provided empirical evidence to show that four visits suffice for uncomplicated pregnancies, and more visits are only recommended in case of complications.

The Gushegu District in Northern Region of Ghana has some of the worst performance indicators with respect to uptake of maternal health services and pregnancy outcome. Though over $86 \%$ of pregnant women have at least one antenatal care (ANC) visit, only $67.5 \%$ complete four or more visits and the majority (83.5\%) report for their first ANC visit after the first trimester [18]. The prevalence of low birth weight (less than 2500 grams at birth) is $14 \%$ of all deliveries conducted in health institutions in the district. Birth weight is a measure of the health status of both the infant and mother and it is influenced by several factors including care during pregnancy, the nutritional and health status before and during pregnancy [18].

The current package of ANC services provided in Ghana includes malaria prevention through intermittent preventive treatment (IPT) and the use of insecticide treated nets, iron and folic acid supplementation and health/nutrition education. Therefore, pregnant women who seek antenatal care early are likely to be cared for and be on prescribed nutrient supplements for a longer duration than those who delay. One therefore expects that ANC services would impact positively on birth outcomes of women who utilize them.

\section{Problem Statement}

Though a number of studies have reported a positive relationship between ANC utilization and birth weight mostly in the developed countries, little is known about the relative contribution of care during pregnancy on birth weight in developing country setting where other equally important predictors of LBW including poverty, malarial infection and poor diet predominate. It is on the basis of this that this study investigated the effect of adequate prenatal care utilization on delivery of LBW babies within a group of women in a socioeconomically deprived environment like the Gushegu District of Northern Ghana.

\section{Objectives of the Study}

Our study was designed to (i) estimate patterns of prenatal care use, (ii) identify factors associated with making at least four prenatal care visits, and (iii) evaluate the association between adequate prenatal care and LBW.

\section{Ethical Clearance}

Permission for the study was obtained from authorities of the Gushegu District Administration. Ethical clearance was also sought and obtained from the School of Medicine and Health Sciences (SMHS) Ethics Committee, UDS. Each study participant after being briefed and offered the opportunity to ask questions about the study, was provided with individual informed written consent form to sign or thumbprint

\section{SUBJECTS AND METHODS}

\section{Study Area}

The study was conducted in the Gushegu district, a socio-economically deprived environment in Northern Ghana. Chronic malnutrition is high and malaria is endemic.

\section{Study Design and Sampling}

A comparative cross sectional study design was used. Women who delivered singleton live birth six months prior to the start of the study constituted the study sample. It compared birth weight of infants born to women who received adequate prenatal services to the birth weight of infants born to women who did not receive adequate care services.

The required sample size was calculated based on the standard formula for one point sample estimation. The primary outcome variable used to estimate the sample size was the population proportion of LBW $(14.0 \%)$ in the study area. A sample size of 186 was required to ensure that the estimated prevalence of the main outcome variable was within plus or minus $5 \%$ of the true prevalence at $95 \%$ confidence level. Assuming a correction factor of 2 (the "design effect") for cluster sampling the sample size was increased to 372 . A non response rate of $10 \%$ and other unexpected events (e.g. damaged/incomplete questionnaire) was factored in the sample size determination and so the final sample size was adjusted to 410 .

Using a two-stage Probability Proportionate to Population Size (PPS) sampling methodology, 410 
households were randomly selected from 30 clusters. The sampling frame of communities was constructed using population data projected by the Ghana Health Service (GHS) from the 2000 population census. The definition of the household used for this survey was "person or a group of persons, related or unrelated, who live together in the same dwelling unit and share at least one meal per day". In each cluster, a complete list of all households was compiled and systematic random sampling used in selecting study participants. All the households in each cluster were serially numbered; the total number of households in a cluster was divided over the sample size to give the sampling interval. The first household was randomly selected by picking any number within the sample interval. Subsequent selections were made by adding the sampling interval to the selected number in order to locate the next household to visit. If the selected household does not have a target respondent, then next household was selected using the systematic sampling procedure. This was done until the sample size was obtained. A maximum of 13 or 14 post partum women were randomly selected from a cluster giving a total of 410 respondents. Only one eligible participant was selected from each household using simple random sampling.

\section{Inclusion and Exclusion Criteria}

All post-partum women who delivered singleton live birth six months prior to the start of the study were eligible for selection. Women whose babies were not weighed at birth and those who were preterm $(<37$ weeks) were however excluded.

\section{Data Collection}

Structured questionnaire was used by trained nurses under the supervision of field supervisors to collect the required data. The primary outcome variable was birth weight of the newborn baby. Structured questionnaire was used to collect information on the independent variables which comprised amount and timing of prenatal care utilization, educational attainment of mother, age of mother, parity, marital status, religion, ethnicity, illness during pregnancy, height and weight of the mother. Maternal height was measured to the nearest $0.1 \mathrm{~cm}$ on the participant's first visit to the antenatal clinic. The Seca 767 digital adult scale was used to weigh participants to the nearest $0.05 \mathrm{~kg}$.

Secondary data including gestational age at first ante-natal care, length of gestation, blood pressure
(BP), haemoglobin $(\mathrm{Hb})$, uptake of Sulphadoxine pyrimethamine (SP) and urinalysis for sugar was also extracted from individual maternal health records. Uptake of SP tablets was supervised by nurses at antenatal clinics and recorded in the maternal health records booklet provided to each pregnant woman. Self -reported cases of malarial infection during the present pregnancy was obtained from individual women.

\section{Measurement of Adequacy of Prenatal Care}

The adequacy of prenatal care was measured using the Adequacy of Prenatal Care Utilization Index (APNCU) [19], modified according to the minimum four visits recommend by the World Health Organization (WHO) for developing countries.

\section{Assessment of Gestational Age and Infant Birth Weight}

Accurate estimation of gestational age is a fundamental issue that is essential in the validity and interpretation of anthropometric outcome measures such as birth weight. Gestational age on first booking at the ANC was assessed using last menstrual period (LMP) approach. Babies delivered in the health institutions were weighed naked within two hours of delivery. All babies were weighed naked by trained midwives on a standard baby weighing scale, to the nearest $1.0 \mathrm{~g}$. Babies delivered at home and whose weight was recorded within three days of delivery by Community Surveillance Volunteers were also included. Infants with birth weight $<2500$ grams were considered as low birth weight and with birth weight $\geq$ 2500 grams as normal.

\section{Determination of Educational Level}

The educational level of mothers was based on the highest level attained according to the Ghanaian System where primary education consist of six years of formal education, up to Junior High School (JHS) is nine years, and up to Senior High School (SHS) is 13 years. An individual with tertiary level education spends at least 17 years acquiring formal education. The educational levels were categorized into low and high. Low represented women who had formal education up to Junior Secondary School. High education represented women who completed at least SHS.

\section{Data Analysis}

Relative risks of low birth weight were estimated for different levels of prenatal care received by mothers, 
controlling for a variety of economic, sociodemographic, and medical factors which may influence birth outcome. Factors which tend to influence mothers into getting or not getting prenatal care were also analyzed. Multiple unconditional logistic regression models were performed to examine the independent effect of antenatal care utilization on the likelihood of delivering a low birth weight (LBW) baby. The measure of association between potential determinants (for example, prenatal care, maternal characteristics, and sickness during pregnancy) and birth weight was examined in two ways: (a) birth weight in grams was regressed on the set of independent variables in a multivariable linear regression analysis and (b) birth weight was classified as a dichotomous dependent variable, with weight less than $2500 \mathrm{~g}$ defined as LBW in a logistic regression analysis.

Odds ratio and $95 \%$ confidence intervals $(\mathrm{Cl})$ were used to assess the strength of association between outcome variable and independent factors.

\section{Ethical Considerations}

The study protocol was presented to the Ethics Committee of the School of Medicine and Health Sciences, University for Development Studies for approval. Verbal informed consent was sought from all study participants before the commencement of any interviews or study activity. Study participants were free to refuse or withdraw from the study at any time without any penalty. The study's purpose and objectives were explained to each participant prior to interview.

\section{RESULTS}

Out of the 410 interviews, a total of 407 complete set of questionnaires were used in the analysis because three of them were incomplete. So this gave a response rate of $99.3 \%$. We only analyzed the birth weight of full term babies excluding preterm deliveries.

\section{Socio-Demographic Characteristics of the Sample}

Most of the participants, $97.5 \%$ (397) were married whilst the rest were either single or living with their partners. A total of $61.9 \%$ (252) of the study participants reported they were not in any gainful employment. With respect to education, $89.4 \%$ (364) of the participants have had no form of formal education at all whereas $7.4 \%(30)$ attained low level of education. Only $3.2 \%$ (13) were educated beyond Senior High Secondary. Most of the mothers $79.6 \%$ (324) were in the 20-34 year group. Table 1 shows that only a small proportion of women $30.2 \%$ (123) made their first antenatal in the first trimester.

\section{Utilization of Prenatal Care}

In these analyses, prenatal care was dichotomized as $0-3$ visits and at least four visits. Of the 407 women, $96.6 \%$ (393) had accessed prenatal care at least once but only $52.1 \%$ (212) made at least four visits. Majority of the women $69.8 \%$ (284) made their first antenatal visit later than the first trimester. In this study we defined inadequate utilization as either starting prenatal care after the $4^{\text {th }}$ month of pregnancy and/ or making

Table 1: Socio-Demographic Characteristics of the Sample ( $N=407$ )

\begin{tabular}{|c|c|c|}
\hline Characteristic & Mean & SD \\
\hline Maternal Age (years) & 27.1 & 5.5 \\
\hline Weight $(\mathrm{Kg})$ at recruitment & 54.3 & 6.6 \\
\hline Mean gestational age on first ANC visit (weeks) & 17.6 & 1.5 \\
\hline Gestational age at first visit & $\%(n)$ & \\
\hline $0-13$ weeks & $30.2(123)$ & \\
\hline 14-27 weeks & $60.4(246)$ & \\
\hline $28^{+}$weeks & $9.3(38)$ & \\
\hline At least three & $62.4(254)$ & \\
\hline
\end{tabular}


less than the recommended $\mathrm{WHO}$ four visits. Adequate care is that begun in the first trimester and a minimum of 4 expected visits being made. The rate of adequate prenatal care utilization based on this modified Adequacy of Prenatal Care Utilization (APNCU) Index among women in our study sample was only $24.8 \%$ (101).

With regards content, mothers reported receiving essential services during ANC. For example, 191 (46.9 $\%$ ) of mothers recalled they received messages or educated on health and nutrition issues, 147 (36.1\%) had their urine tested whilst $210(51.6 \%)$ had their blood tested. On tetanus toxoid injection, 317(77.9\%) were given the immunization. Of the 407 women, 181 (44.5\%) were tested for HIV and 393 (96.6\%) received at least one dose of SP.

A composite index of seven of the essential services received during ANC was created by assigning a score of 1 for having received a particular service and zero for not receiving the service. The total score for each woman was then categorized as low (< 4 ) or high ( $\geq 4)$. The bivariate cross tabulation of this ANC content and LBW shows low ANC content is a risk factor for LBW. The proportion of LBW among women who were classified as low was significantly higher compared to women who received high ANC content
(46.4\% versus $16.1 \%)$ (Chi-squared $=16.1, \mathrm{p}<$ $0.001)$.

\section{Relationship Between Selected Variables and 4 Plus ANC Visits}

The study subjects were divided in two groups on the basis of either making at least four antenatal care visits or not. When maternal age, educational status of women, husband's education and malarial infection during pregnancy were compared between the two groups, the strongest predictors of making at least four ANC visits were high maternal educational attainment, maternal age and husband's occupation being a Civil Servant (Table 2).

Women less than 20 years of age and women who were at least 35 years attended fewer antenatal sessions, compared to women in the 20-34 year age group. Bivariate analysis showed that husband's rather than maternal occupation was a predictor of 4 plus prenatal visits.

In a multiple logistic regression analysis, the major factor that independently predicted 4 plus ANC visits was maternal educational attainment. Compared to women of no formal education, women who attained at least secondary level education were 11 times more likely to attend ANC for more than four times during

Table 2: Comparison of Between Low and High ANC Attendees by Socio-Demographic Characteristics

\begin{tabular}{|c|c|c|c|c|}
\hline \multirow[b]{2}{*}{ Variable } & \multirow[b]{2}{*}{$\mathbf{N}$} & \multicolumn{2}{|c|}{ Classification of ANC visits } & \multirow{2}{*}{ Test statistic } \\
\hline & & $\begin{array}{l}0-3 \text { times } \\
\text { n (\%) }\end{array}$ & $\begin{array}{c}\text { At least } 4 \text { times } \\
n(\%)\end{array}$ & \\
\hline \multicolumn{5}{|l|}{ Age (years) } \\
\hline Less than 20 & 41 & $26(63.4)$ & $15(36.6)$ & \multirow{3}{*}{$\begin{array}{c}\text { Chi-square } \\
\left(x^{2}\right)=7.8 \\
p=0.02\end{array}$} \\
\hline $20-34$ & 324 & $144(44.4)$ & $180(55.6)$ & \\
\hline$\geq 35$ & 42 & $25(59.5)$ & $17(40.5)$ & \\
\hline \multicolumn{5}{|c|}{ Husband's occupation } \\
\hline Trader & 37 & $18(48.6)$ & $19(51.4)$ & \multirow{3}{*}{$\begin{array}{l}x^{2}=8.3 \\
p=0.016\end{array}$} \\
\hline Farmer & 347 & $172(49.6)$ & $175(50.4)$ & \\
\hline Civil service & 23 & $5(21.7)$ & $18(78.3)$ & \\
\hline \multicolumn{5}{|l|}{ Education } \\
\hline None & 360 & $180(50.0)$ & $180(50.0)$ & \multirow{3}{*}{$\begin{array}{l}x^{2}=8.7 \\
p=0.012\end{array}$} \\
\hline Low & 30 & $14(46.7)$ & $16(53.3)$ & \\
\hline High & 17 & $5(29.4)$ & $12(70.6)$ & \\
\hline \multicolumn{5}{|c|}{ Malaria during pregnancy } \\
\hline Yes & 135 & $74(54.8)$ & $61(45.2)$ & \multirow{2}{*}{$\begin{array}{l}x^{2}=3.9 \\
p=0.05\end{array}$} \\
\hline No & 257 & $114(44.4)$ & $143(55.6)$ & \\
\hline
\end{tabular}


Table 3: Relationship Between Selected Variables and Low Birth Weight (LBW)

\begin{tabular}{|c|c|c|c|c|}
\hline Factor & $\mathbf{N}$ & $\begin{array}{c}\text { Normal Weight } \\
n(\%)\end{array}$ & $\begin{array}{l}\text { LBW } \\
\text { n (\%) }\end{array}$ & Test statistic \\
\hline \multicolumn{5}{|l|}{ Age (years) } \\
\hline $35+$ & 20 & $13(65.0)$ & $7(35.0)$ & $\begin{array}{c}\text { Chi-square } \\
\left(x^{2}\right)=8.61 \\
p=0.014\end{array}$ \\
\hline \multicolumn{5}{|c|}{ Timing of first ANC visit } \\
\hline Late Initiation & 284 & $224(78.9)$ & $60(21.1)$ & $\begin{array}{c}x^{2}=5.5 \\
p=0.019\end{array}$ \\
\hline \multicolumn{5}{|c|}{ Frequency of ANC Visits } \\
\hline None & 7 & $0(0.0)$ & $7(100.0)$ & \multirow{2}{*}{$\begin{array}{l}x^{2}=52.7 \\
p<0.001\end{array}$} \\
\hline 1-3 times & 188 & 139 (73.9) & $49(26.1)$ & \\
\hline None & 364 & $293(80.5)$ & $71(19.5)$ & \multirow{3}{*}{$\begin{array}{c}x^{2}=4.67 \\
p=0.09\end{array}$} \\
\hline Low & 30 & $27(90.0)$ & $3(10.0)$ & \\
\hline High & 13 & $13(100.0)$ & 0.0 & \\
\hline \multicolumn{5}{|l|}{ SP Doses taken } \\
\hline None & 17 & $6(35.3)$ & $11(64.7)$ & \multirow{3}{*}{$\begin{array}{c}x^{2}=35 \\
p<0.001\end{array}$} \\
\hline $1-2$ & 187 & $145(77.5)$ & $42(22.5)$ & \\
\hline $3-4$ & 203 & $182(89.7)$ & $21(10.3)$ & \\
\hline \multicolumn{5}{|l|}{ ANC Content } \\
\hline Low & 28 & $15(53.6)$ & $13(46.4)$ & $\begin{array}{l}x^{2}=16.1 \\
p<0.001\end{array}$ \\
\hline
\end{tabular}

pregnancy $(\mathrm{AOR}=11.3, \mathrm{Cl}: 1.4-89.2), \mathrm{p}=0.02$. Women who reported having malaria were $38 \%$ less likely of making at least four visits, compared with women who reported not having malaria during the pregnancy $(\mathrm{AOR}=0.62, \mathrm{Cl}: 0.40-0.95), \mathrm{p}=0.03$.

On timing of prenatal care utilization, maternal age of 30 years and younger ( $\mathrm{AOR}=0.55, \mathrm{Cl}$ : $0.37-0.82$ ) and high educational attainment $(\mathrm{AOR}=0.32, \mathrm{Cl}: 0.18$ $0.55)$ were protective factors against late reporting for prenatal care. This means women who were older than 30 years and low educational attainment were significantly more likely to begin prenatal care after the first trimester. Young mothers and more highly educated women were significantly more likely to begin care in the first trimester. Malarial infection was rather a risk factor for late initiation of prenatal care $(A O R=2.2$, Cl: 1.4 - 3.5).

\section{Relationship Between Selected Variables and Low Birth Weight (LBW)}

Table 3 shows bivariate analysis of variables that were associated with LBW. Frequent ANC utilization, early initiation of ANC, and uptake of SP were protective against delivering LBW baby.

\section{Relationship Between ANC Utilization and Birth Weight}

In the whole sample, infants born to women who made at least four ANC visits were, on average, $797 \mathrm{~g}$ heavier than infants of women who did not attend prenatal care visits at all $(\mathrm{P}<0.001,95 \%$ confidence interval $[\mathrm{Cl}]=331,1,263)$. After adjustment for number of SP doses received and number of pregnancies of the woman (gravidae), this difference was reduced to an estimated $633 \mathrm{~g}$ (Cl: 126, 1,140), $\mathrm{p}=0.009$ (Table 4).

The effect of ANC utilization on birth weight was different for unemployed and employed women as a consequence of a strong interaction between employment status and frequency of prenatal care utilization $F(1,407)=5.2, p=0.02$. The difference in the adjusted mean birth weight among unemployed women who made at least four ANC visits and those who did not attend ANC was $778 \mathrm{~g}$ (Cl: $233-1,322, \mathrm{p}$ 
Table 4: Sidak Pairwise Comparisons of Mean Birth Weight $(\mathrm{Kg})$

\begin{tabular}{|c|c|c|c|c|c|c|}
\hline \multirow{2}{*}{$\begin{array}{c}\text { (I) ANC } \\
\text { attendance }\end{array}$} & \multirow{2}{*}{ (J) AN attendance } & \multirow{2}{*}{ Mean (I-J) } & \multirow{2}{*}{ Std. Error } & \multirow{2}{*}{ Sig. ${ }^{a}$} & \multicolumn{2}{|c|}{ 95\% Confidence Interval for Difference } \\
\hline & & & & & Lower Bound & Upper Bound \\
\hline \multirow{2}{*}{ None } & $1-3$ times & -0.400 & 0.20 & 0.140 & -0.89 & 0.09 \\
\hline & At least 4 times & $-0.633^{*}$ & 0.21 & 0.009 & -1.14 & -0.13 \\
\hline \multirow{2}{*}{$1-3$ times } & None & 0.400 & 0.20 & 0.140 & -0.09 & 0.89 \\
\hline & At least 4 times & $-0.233^{*}$ & 0.06 & $<0.001$ & -0.37 & -0.10 \\
\hline \multirow{2}{*}{ At least 4 times } & None & $0.633^{*}$ & 0.21 & 0.009 & 0.13 & 1.14 \\
\hline & $1-3$ times & $0.233^{*}$ & 0.06 & $<0.001$ & 0.10 & 0.37 \\
\hline
\end{tabular}

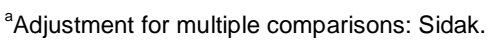

$=0.002)$. However, among working mothers, the difference in terms of birth weight between $4^{+}$ANC attendees and non attendees was not significantly different.

Similarly babies born to women who made their first ANC visit in the first trimester were significantly heavier than babies born to women who made the first visit in the third trimester $(3036 \mathrm{~g}$ versus $2,720 \mathrm{~g}), \mathrm{F}(1,399)=$ $5.97, p=0.003$.

\section{Determinants of LBW}

Table 5 shows the independent determinants of LBW in the study sample. The predictors of birth weight as both a continuous and categorical variable were the same and so only those of LBW (categorical variable) are presented in this report. Variables entered into the logistic regression model but were insignificant were haemoglobin concentration at first ANC visit, weight of mother in the first trimester, frequency of malarial infection, gender of baby, and maternal educational level.

The incidence of low birth weight (LBW) of newborn babies was $18.2 \%$ (74/407). ANC utilization of at least four visits had $63.0 \%$ protection against delivering a LBW $(A O R=0.37,95 \% \mathrm{Cl}: 0.19,0.69)$. The protection was increased to $70 \%$ among women who were unemployed $(\mathrm{AOR}=0.30,95 \% \mathrm{Cl}: 0.13,0.70)$. High ANC content was also protective of LBW but increased gravidity was a risk factor for LBW.

\section{DISCUSSION OF RESULTS}

In this study we examined timing and utilization of prenatal care and their effect on birth and low birth weight. The main findings are discussed as follows:

\section{Utilization of Prenatal Care}

Prenatal care has been measured using various indicators such as the number of prenatal care visits, the number of prenatal care visits adjusted for the length of the pregnancy, timing of first prenatal care visit, and Adequacy of Prenatal Care Utilization (APNCU) Index. The APNCU index, proposed by Kotelchuck, is comprised of two parts: the month in which prenatal care is initiated and the number of visits from initiation of care until delivery [19].

In this study we defined inadequate prenatal care utilization as either starting prenatal care after the $3^{\text {rd }}$

Table 5: Determinants of LBW

\begin{tabular}{|l|c|c|c|}
\hline \multirow{2}{*}{ Variable } & \multirow{2}{*}{$\operatorname{Exp(B)}$} & Lower & 95\% C.I.for EXP(B) \\
\cline { 3 - 4 } & & 1.01 & 1.26 \\
\hline \hline Gravidity & 1.13 & 0.46 & 0.89 \\
\hline SP Doses taken & 0.64 & 0.19 & 0.69 \\
\hline $4^{+}$ANC visits & 0.37 & 0.73 & 0.97 \\
\hline High ANC Content & 0.84 & & \\
\hline Constant & 1.92 & & \\
\hline
\end{tabular}


month of pregnancy and/or making less than the recommended $\mathrm{WHO}$ four visits. Adequate prenatal care was defined as one that initiated in the first trimester and a minimum of four expected visits made. However, including the dimension of early initiation of prenatal care substantially changed the proportion of mothers receiving adequate care. In effect, the rate of adequate prenatal care utilization based on this modified APNCU index among women in our study sample was only 24.8 $\%$. This means a few women in our sample satisfied the criteria of adequate utilization of antenatal care based on this modified APNCU index. In principle, the application of this index for purposes of classification may present some difficulties because the WHO recommends a minimum of four visits for women with uncomplicated pregnancies. The modified APNCU will however classify all women who initiate prenatal care after 12 weeks as receiving inadequate care regardless of the number of visits made.

Though patronage for prenatal care (that is, $4^{+}$ANC visits) is reported to have improved from $62.8 \%$ in 2007 to $81.6 \%$ in 2010 nationally [20], vast regional differences remain. Evidence from this study showed that though majority of the women attended antenatal care (ANC) at least once, a low proportion (30.2\%) of the women made the first ANC visit within the first trimester of pregnancy and only $52.1 \%$ made at least four visits. Prenatal care is more likely to be effective if women begin receiving care in the first trimester of pregnancy and continue to receive care throughout pregnancy, according to accepted standards of periodicity [21].

The World Health Organization (WHO) Technical Working Group on Antenatal Care established four as the minimum number of prenatal care visits for women without identified problems in order to take advantage of health services including blood pressure measurement, urine testing for detecting bacteria and protein in urine, blood testing to detect syphilis and severe anemia, weight and height measurements [16, 22]. Villar et al. [17], provided empirical evidence to show that four visits suffice for uncomplicated pregnancies, and more visits are only recommended in case of complications. The first ANC visit should be as early as possible after confirmation of pregnancy. The standard recommended number of ANC visits in Ghana is monthly visits up to 28th week of pregnancy, followed by bi-weekly visits to the 36th week of pregnancy, and weekly visits afterwards to delivery.
Factors Affecting Timing and Adequate Utilization of Prenatal Care

Since 2003, the Government of Ghana has promoted access to maternal health services including prenatal care through the free maternal health policy in the four most deprived regions of the country; Central, Upper East, Upper West and the Northern regions. The policy was extended to the remaining six regions of the country in 2005. The aim of the policy is to reduce the financial barriers in using maternity services including ANC. With the free maternal health policy in place, there is still a relative low patronage of adequate ANC in the study population suggesting other factors may be responsible for the trend. For example, financial constraints including transportation cost to and from prenatal care centres could ultimately affect access to services. Furthermore, our data showed that the major risk factors for late initiation of prenatal care were malarial infection during pregnancy, old maternal age and low educational attainment. Young mothers and more highly educated women were significantly more likely to begin care in the first trimester.

These results corroborate findings reported elsewhere that similar maternal characteristics are associated with the poor use of prenatal care among Asian American ethnic groups [23].

The number of prenatal visits made by a woman to some extent is influenced by gestational length. However, adjusting for this in data analysis may introduce some bias because gestational length is itself a birth outcome that is so strongly correlated with birth weight [24].The best approach therefore is to do the analysis within strata (full term or preterm deliveries). In our analysis we did not include preterm deliveries because of these reasons.

The findings of this study showed that educational attainment of the mother and the type of husband's occupation were key determinants of a woman's ability to make at least four prenatal visits. Women with low educational level and whose husbands were farmers were least likely to make the minimum required visits. Several other studies have reported that education of women is positively associated with utilization of antenatal care [25-27].

There are several potential pathways that could explain why maternal education is consistently and strongly associated with many health seeking behaviours. More education might lead to more 
decision-making power for the mother within her household, in which case women develop greater confidence and capabilities to make decisions regarding their own health, as well as take important actions including early initiation of prenatal care. Also, education might increase her knowledge of modern health care and its importance, thereby being better informed to make better choices. Furthermore, higher education attainment might be associated with a higher living standard because of increased earnings or because of a wealthier husband. Educated women may thus have greater financial ability to access health care. The level of education of the mother might be correlated with several other factors that can be assumed to influence the timing and utilization of antenatal care services.

The findings of this study also showed that older mothers were more likely to initiate prenatal care late. This may be due to several factors including the fact that women of higher age draw on their maternity experience and may not feel the need to receive professional care if previous deliveries were uncomplicated. This might also due to women in the older age group are more likely to have many children to care of and may find it difficult accessing prenatal care. Younger women on the other hand are just starting child bearing and may consider themselves to be in a high risk group and may thus seek care early. Also, often a high value is placed on the first pregnancy and in some settings the woman's natal family helps her get the best care possible.

Our finding that advanced maternal age, i.e. pregnancies in women aged 35 and older was associated with late initiation of prenatal care should be a source of worry because this group of women is known to be of increased risk for pregnancy related complications. Many of these risks can be successfully managed through preconception and prenatal care. Focused care for women over age 35 plays a vital role in minimizing health risks and maximizing health opportunities to achieve the best possible outcome, a healthy baby and a healthy mother. If for some reasons this group of women does not access care early, then they will be missing all the opportunities that come with prenatal care.

With regards to malarial infection during pregnancy we expected women without malaria to seek late prenatal care in comparison to women with malarial infection. However, the reverse was the case in this study sample. One would expect a sick person to seek care first.

Other potential barriers including perceived intervention inefficacy, lack of spousal support, cultural beliefs, and time constraints may also be blamed for the under utilization of prenatal services. Socio-cultural practices may also contribute to the under-utilization of antenatal services. According to Griffiths \& Stephenson [28], in traditional societies where restrictions are placed on women's freedom of movement and contact with unrelated men, a husband's attitude toward prenatal care may be an important factor in determining whether prenatal care is received.

A recent study conducted in the Northern Region of Ghana showed that household decision makers (HDMs) - especially partners and grandmothers/fathers wield significant power and dictate where, when and with whom women and neonates should seek care during critical times (in pregnancy, delivery and neonatal periods. Women expressed a sense of powerlessness at always having to rely on the permission, support and approval of the HDMs to use Maternal and Newborn Care services even at critical points in their lives [29].

\section{Determinants of LBW}

LBW can result from premature birth (duration of pregnancy less than 37 weeks from the last menstrual period), inadequate foetal growth or a combination of the two [30, 31]. Intra-uterine growth restriction (IUGR) is more associated with LBW in developing countries like Ghana.

The results of this study suggest that adequate antenatal care utilization is effective in preventing LBW even after controlling for strong predictors of birth weight. This confirms the fact that antenatal care does have a direct influence on LBW in not only in urban but rural settings as well. Its effect was more discernible among women who were not in gainful employment (suggestive of low socio-economic status).

In assessing the independent effect of ANC, potentially confounding variables including gravidity, maternal age, marital status, maternal height, and malarial infection during pregnancy, uptake of SP and mother's education were adjusted for in logistic regression analysis. The important determinants of LBW were uptake of prenatal care services, SP intake, and gravidity. 
Other additional behaviors which can negatively affect birth weight are poor maternal diet, smoking and consumption of alcoholic beverages during pregnancy. However, none of these was a strong predictor of weight at birth in our sample. Interestingly, though maternal educational level was an important determinant of ANC utilization, it contributed insignificantly to protection against delivering a LBW baby, perhaps because there was very little variation in maternal education in the study sample. Nearly $90 \%$ of the study participants had no formal education.

\section{Relationship Between Adequate Prenatal Care and Low Birth Weight}

We investigated the independent effect of three aspects of prenatal care [that is, timing, amount and adequacy of prenatal care utilization (APNCU)]. A modified Adequacy of Prenatal Care Utilization Index which combines information on timing and amount of care was used to quantify adequacy of prenatal care. A woman was thus classified as having received adequate of prenatal care if she initiated first ANC in the first trimester and made a minimum of four prenatal visits).

Though in bivariate analyses, early initiation of first ANC visit and the modified APNCU adequacy index were negatively associated with the incidence of LBW, these associations were not sustained in multiple logistic regression analysis when other covariates were controlled for. Only frequency of antenatal care had an independent positive association with LBW. Though early initiation of care has been a recommended goal for many prenatal programmes, its effect on LBW compared to the number of prenatal visits was insignificant in this study sample. It appears early initiation of prenatal care was not an important determinant of LBW in the study sample perhaps, because of the low proportion of women who made the first ANC visit in the first trimester. Women who initiated ANC early in the first trimester had a better chance of making at least four routine visits and so this indicator (that is, 4 plus visits) appears adequate for analyzing associations between prenatal care and LBW, especially in populations where few women start prenatal care in the first trimester.

The findings of the current study analysis showed a strong positive relationship between the frequency of antenatal visits and increased birth weight of the baby and this is consistent with many previous studies that have reported increased utilization of prenatal care is effective in lowering the risk of LBW. Early and adequate utilization of prenatal care have long been thought of as the primary defenses against pregnancy complications and adverse birth outcomes such as preterm births, low birth weight. This implies late prenatal care use could result in adverse birth outcomes.

What then could possible account for the inverse association between utilization of prenatal care services and the incidence of LBW? The effect of prenatal care does not just depend on mere occurrence of a visit but on the quantity and quality of services received during the visit. These essential services include health and nutrition education, anthropometric measurements, assessment of fetal heart sounds, and blood pressure check up, testing for anaemia, malaria and the administration or supply of nutrient supplements such as iron and folic acid tablets. These assessments help in identifying potentially modifiable risk factors, such as low pre-pregnancy weight, low gestational weight gain, alcohol consumption, poor dietary habits, many of which may be mitigated or prevented through quality ANC. Adequate prenatal care utilization may be protecting against LBW through many mechanisms including ensuring adequate nutrition and vitamin intake, proper vaccination and negative behavioral modification. Vitamins and minerals help repair and maintain cells and tissues. For example, iron tablets help prevent iron deficiency anemia which could lead to increased risk of preterm delivery and infant low birth weight.

It needs to be pointed out however, that the effect of frequent antenatal visits on pregnancy outcomes such as birth weight may be distorted by self selection bias among women who seek ANC services. Both favourable and adverse self selection processes can bias the measure of association between prenatal care utilization and birth outcome. For example, healthier women who receive more prenatal care may also have a more positive health behavior (that is, favorable selection), and so the effect of prenatal care may be overestimated. On the occasion of favorable self selection, such women have positive health behaviors and so usually at lower risk of a low birth weight. In addition to these health conscious women being more likely to initiate prenatal care early and to maintain a regular schedule of visits, they can equally adopt other positive behaviours such as selecting high quality providers or eating diversified diet. Consequently, positive birth outcomes will be a function not only of prenatal care adequacy but in addition of these health- 
promoting behaviors and attitudes. This could potentially lead to a positive bias on estimates of prenatal care adequacy [32, 33]. In an observational study, it is unlikely that all of these confounding factors can be controlled for.

On the other hand, if women receive more prenatal care because of poorer health state during pregnancy (that is, adverse selection), then the effect of prenatal care may be underestimated. In situations where adverse selection of women occurs and who by virtue of their own poor health status will tend to use prenatal care services more. In such circumstances, a higher probability of a negative birth outcome is inevitable and will underestimate the impact of prenatal care on birth outcome.

Our findings are consistent with previous studies that investigated the association between birth outcome and several aspects of ANC mostly conducted in urban settings of developed countries. For example, some studies found that higher prenatal care visits increase birth weight [31, 34-41]. On the other hand, inadequate use of prenatal care is associated with higher risk of LBW $[42,43])$. An increase in the quality of prenatal care increases birth weight [39, 44]. Whereas delay in seeking prenatal care increases the risk of low birth weight [45], early initiation of prenatal care (first trimester) leads to a reduction in low birth weight [8, 45, 46]. Among Asian Americans, early access to and adequate use of prenatal care have been associated with positive birth outcomes [47, 48].

In contrast, there are a number of studies that have shown that uptake of ANC services does not have positive on pregnancy outcome. For example, Garrido [49] reported that prenatal care appears to have no statistically significant impact in rural areas, a situation that was attributed to poor quality in service when providing prenatal care. Quality of care in that study was measured in terms of whether or not the mother had tetanus vaccination during pregnancy. Warner [8] also showed that the number of prenatal care visits appeared to have no statistically significant effect on birth weight but that early prenatal care initiation has a positive impact on birth weight.

\section{Conclusion/Recommendations}

We compared birth weight across groups of women with different patterns of prenatal care utilization. The findings of this observational study show a strong positive association between amount of prenatal care utilization and LBW in rural setting of Northern Ghana where other predictors of birth weight including malarial infection, poor diet and poverty prevail.

Low educational attainment and husband being a farmer were the main risk factors for low uptake of prenatal services. Women who were older than 30 years and low educational attainment were significantly more likely to begin prenatal care after the first trimester.

In order to prevent the prevalence of LBW babies, efforts to increase scheduled visits in antenatal care must target especially women who are older than 30 years and those who are not gainfully employed.

\section{Limitation of Study}

There are some limitations of the findings of this study. Ideally, the efficacy of prenatal care is best investigated through randomized controlled trials. However, this kind of study design is no longer possible because of ethical reasons. Therefore, evaluation of the effect of prenatal care on birth outcomes must rely mostly on observational studies [50, 51].

To reduce confounding due to preterm delivery, we use only full term deliveries data in the analysis. Our analysis was also limited to singleton live births; therefore, multiple births were not represented. However, a major obstacle to valid inferences about the effect of prenatal care utilization on birth outcomes in an observational study of this nature is self selection bias. We could not rule out selection bias, for women who receive adequate prenatal care may also be more likely to experience better pregnancy outcomes because of other characteristics which have independent positive influences on pregnancy outcomes including birth weight [34, 52].

Several indices have been developed to examine the adequacy of prenatal care and these usually take into account the number of prenatal care visits, the time of the first prenatal care visit and the gestational age. However, none of these indices has been able to resolve the problem of self selection bias $[51,53]$. In addition, the analyses were limited to utilization of prenatal care but not quality of care.

\section{ACKNOWLEDGEMENT}

The authors gratefully acknowledge the involvement of all the women and community leaders whose cooperation led to a successful data collection 
experience. We very much appreciate the input and support received from the Gushegu District Health Management team (DHMT).

\section{REFERENCES}

[1] WHO: World Health Statistics 2008. Geneva: WHO 2008.

[2] Morris SS, Victora CG, Barros FC, Halpern R, Menezes AB, Cesar JA, et al. Length and ponderal index at birth: associations with mortality, hospitalizations, development and post-natal growth in Brazilian infants. Int $\mathrm{J}$ Epidemiol 1998; 27: 242-47.

http://dx.doi.org/10.1093/ije/27.2.242

[3] Barker DJP. The origins of the developmental origins theory. J Inter Med 2007; 261: 412-17.

http://dx.doi.org/10.1111/j.1365-2796.2007.01809.x

[4] De Boo HA, Harding JE. The developmental origins of adult disease (Barker) hypothesis. The Royal Australian and New Zealand College of Obstetricians and Gynaecologists 2006; 46: 4-14.

http://dx.doi.org/10.1111/j.1479-828X.2006.00506.x

[5] Black SE, Devereux P, Salvanes KG. From the Cradle to the Labor Market? The Effect of Birth Weight on Adult Outcomes. Quarterly J Econom 2007; 22(1): 409-39. http://dx.doi.org/10.1162/ajec.122.1.409

[6] Oreopoulos P, Stabile M, Walld R, Roos L. Short, Medium, and Long Term Consequences of Poor Infant Health: An Analysis Using Siblings and Twins. J Infect Dis Human Resour 2008; 43(1): 88-138.

[7] IOM (Ed.). Unequal Treatment: Confronting Racial and Ethnic Disparities in Healthcare. Washington, DC.: The National Academies Press 2005.

[8] Warner G. Prenatal Care Demand and Birthweight Production of Black Mothers. Am Econom Rev 1995; 85(2): 132-37.

[9] Liu GG. Birth Outcomes and the Effectiveness of Prenatal Care. Health Services Res 1998; 32(6): 805-23.

[10] Rous JJ, Jewell RT, Brown RW. The effect of prenatal care on birthweight: a full-information maximum likelihood approach. Health Econom 2003; 13: 251-64. http://dx.doi.org/10.1002/hec.801

[11] Smith Conway K, Partha D. Is Prenatal Care Really Ineffective? Or, is the 'Devil' in the Distribution?" Hunter College Department of Economics Working Papers 2004; 02(2).

[12] Krueger PM, Scholl TO. Adequacy of prenatal care and pregnancy outcome. JAOA 2000; 100(8): 485-92.

[13] Deb P, Sosa-Rubi S. Does onset or quality of prenatal care matter more for infant health? HEDG Working Paper 2005; 5(11).

[14] Guilkey DK, Popkin BM, Akin JS, Wong E. Prenatal Care and Pregnancy Outcome in the Philippines. J Develop Econom 1989; 30: 241-72.

http://dx.doi.org/10.1016/0304-3878(89)90003-5

[15] Ministry of Health: Annual report 2007, 2nd ed. edition. Accra, Ghana: Ministry of Health 2007.

[16] WHO: Antenatal Care Department of Technical Working Group 1994 WHO/FRIt/msm/968. Geneva: WHO 1999.

[17] Villar JH, Ba'aqeel G, Piaggio P, Lumbiganon JM, Belizán U, Farnot $\mathrm{Y}$, et al. WHO antenatal care randomized trial for the evaluation of a new model of routine antenatal care. Lancet 2001; 357: 1551-64

http://dx.doi.org/10.1016/S0140-6736(00)04722-X

[18] UNICEF: Multiple Indicator Cluster Survey (MICS). Accra: UNICEF, Ghana Health Service 2009.
[19] Kotelchuck M. An Evaluation of the Kessner Adequacy of Prenatal-Care Index and A Proposed Adequacy of PrenatalCare Utilization Index. Am J Public Health 1994; 84: 141420.

http://dx.doi.org/10.2105/AJPH.84.9.1414

[20] MOH: Annual report 2010, Accra, Ghana: Ministry of Health 2010.

[21] US Department of Health and Human Services: Maternal, Infant, and Child Health. In Healthy People Vol II, . 2nd ed. Washington, DC: Available: http: //www.healthypeople.gov /document/html/volume2/16mich.htm], Accessed 12-102012.

[22] Berg CJ. Prenatal care in developing countries: the World Health Organization Technical Working Group on Antenatal Care. J Am Med Women's Assoc 1995; 50(5): 182-86.

[23] Kogan MD, Alexander GR, Mor JM, Kieffer EC. Ethnicspecific predictors of prenatal care utilisation in Hawaii. Paediatr Perinat Epidemiol 1998; 12: 152-62. http://dx.doi.org/10.1046/j.1365-3016.1998.00105.x

[24] Koroukian SM, Rimm AA. The Adequacy of Prenatal Care Utilization (APNCU) index to study low birth weight: is the index biased? J Clin Epidemiol 2002; 55: 296-305. http://dx.doi.org/10.1016/S0895-4356(01)00471-1

[25] Kwast BE, Luff JM. Factors associated with maternal mortality in Addis Ababa. Ethiopia. Intl Epidemiol 1988; 17: 115-21.

http://dx.doi.org/10.1093/ije/17.1.115

[26] UNICEF: Women's health in Pakistan. In Fact sheets prepared for Pakistan National Forum on Women's Health, Karachi, Pakistan: UNICEF, Pakistan 1997: 16-17.

[27] Hussain MT. Factors affecting the use of antenatal care in Urban Bangladesh. Urban Health Dev Bul 1998; 1-4.

[28] Griffiths P, Stephenson R. Understanding the user's perspectives of barriers to maternal health care in Maharashtra. Indian J Biosocial Sci 2001; 33: 339-59. http://dx.doi.org/10.1017/S002193200100339X

[29] CRS Ghana: Encouraging Positive Practices for Improving Child Survival (EPPICS) Knowledge, Practice and Coverage (KPC) survey, Tamale: Catholic Relief Services 2011.

[30] Kramer MS. Determinants of low birth weight: methodological assessment and meta-analysis. Bull World Health Organ 1987; 65: 663-37.

[31] Institute of Medicine: Preventing low birthweight Washington, DC: National Academy Press 1985.

[32] Frick KD, Lantz PM. Selection Bias in Prenatal Care Utilization: An Interdisciplinary Framework and Review of the Literature. Med Care Res Rev 1996; 53(4): 371-96. http://dx.doi.org/10.1177/107755879605300401

[33] Alexander GR, Korenbrot CC. The Role of Prenatal Care in Preventing Low Birth Weight The Future of Children 1995; 5(1): 103-20.

[34] Kramer MS, Séguin L, Lydon J, et al. Socio-economic disparities in pregnancy outcome: why do the poor fare so poorly? Paediatr Perinat Epidemiol 2000; 14(3): 194-10. http://dx.doi.org/10.1046/.1365-3016.2000.00266.x

[35] Doyle W, Wynn AHA, Crawford MA, et al. Nutritional counseling and supplementation in the second and third trimester of pregnancy, a study in a London population. $J$ Nutr Med 1992; 3(3-4): 249-56. http://dx.doi.org/10.3109/13590849208997980

[36] Scholl TO, Hediger ML, Bendich A, et al. Use of multivitamin/ mineral prenatal supplements: influence on the outcome of pregnancy. Am J Epidemiol 1997; 146(2): 134-41. http://dx.doi.org/10.1093/oxfordjournals.aje.a009244

[37] Haider BA, Bhutta ZA. Multiple-micronutrient supplementation for women during pregnancy [electronic article]. Cochrane Database Syst Rev (CD004905) 2006. 
[38] Shah PS, Ohlsson A. Knowledge Synthesis Group on Determinants of Low Birth Weight and Preterm Births. Effects of prenatal multimicronutrient supplementation on pregnancy outcomes: a meta-analysis. CMAJ 2009; 180(12): E99-E108. http://dx.doi.org/10.1503/cmaj.081777

[39] Nazim NH, Fan L. Does prenatal healthcare improve child birth weight outcomes in Azerbaijan? Results of the national demographic and health survey. Econom Human Biol 2011; 9(1): 56-65.

http://dx.doi.org/10.1016/j.ehb.2010.08.003

[40] Jewell RT, Triunfo P. The Impact of prenatal care on birth weight: The case of Uruguay. Health Econom 2006; 15(11): 1245-50.

http://dx.doi.org/10.1002/hec.1121

[41] Rous JF, Jewell RT, Brown RW. The effect of prenatal care on birth weight: A full-information maximum likelihood approach. Health Econom 2004; 13(3): 251-64. http://dx.doi.org/10.1002/hec.801

[42] Raatikainen K, Heiskanen N, Heinonen S. Under-attending free antenatal care is associated with adverse pregnancy outcomes. BMC Public Health 2007; 7: 268.

http://dx.doi.org/10.1186/1471-2458-7-268

[43] Goldani MZ, Barbieri MA, Silva AAM, Bettiol H. Trends in prenatal care use and low birthweight in Southeast Brazil. Am J Public Health 2004; 94(8): 1366-71. http://dx.doi.org/10.2105/AJPH.94.8.1366

[44] Mwabu G. The production of child health in Kenya: a structural model of birth weight. J Afr Econom 2009; 18(2): 212-60. http://dx.doi.org/10.1093/jae/ejn013

[45] Wehby GL, Murray JC, Castilla EE, Lopez-Camelo JS, Ohsfeldt RL. Qunatile effects of prenatal care utilization on birth weight in Argentina. Health Econom 2009; 18(11): 1307-21. http://dx.doi.org/10.1002/hec.1431
[46] Frank RG, Strobino DM, Salkever DS, Jackson CA. Updated estimates of the impact of prenatal care on birthweight outcomes by race. J Human Lactation Resour 1992; 27(4): 629-42.

http://dx.doi.org/10.2307/146078

[47] Lieberman E, Ryan KJ, Monson RR, Schoenbaum SC. Risk factors accounting for racial differences in the rate of premature birth. N Engl J Med 1987; 317: 743-48. http://dx.doi.org/10.1056/NEJM198709173171206

[48] Alexander GR, Cornely DA. Racial disparities in pregnancy outcomes: the role of prenatal care utilization and maternal risk status. Am J Prev Med 1987; 3: 254-61.

[49] Garrido GG. The impact of adequate prenatal care in a developing country: Testing the WHO recommendations. Available at (www.ttp: //paa2010.princeton.edu/papers/ 100732), accessed on 18-10-2012; 2009.

[50] Fiscella K. Does prenatal care improve birth outcomes? A critical review. Obstet Gynecol 1995; 85: 468-79. http://dx.doi.org/10.1016/0029-7844(94)00408-6

[51] Alexander GR, Kotelchuck M. Assessing the role and effectiveness of prenatal care: history, challenges, and directions for future research. Public Health Rep 2001; 116: 306-16.

[52] Shoham-Vardi I, Levy E, Belmaker I, Mazor M, Goldstein D. Utilisation of prenatal services and birth outcomes: a community-based study in Israel. Paediatr Perinat Epidemiol 1997; 11: 271-86. http://dx.doi.org/10.1111/j.1365-3016.1997.tb00005.x

[53] Kogan MD, Alexander GR, Kotelchuck M, et al. Trends in twin birth outcomes and prenatal care utilization in the United States, 1981-1997. JAMA 2000; 284: 335-41. http://dx.doi.org/10.1001/jama.284.3.335 